Research Article

\title{
Optimization Method for Irregular Piled Raft Foundation on Layered Soil Media
}

\author{
Yunfei Xie ${ }^{1,2}$ and Shichun Chi (iD ${ }^{1,2}$ \\ ${ }^{1}$ State Key Laboratory of Coastal and Offshore Engineering, Dalian University of Technology, Dalian, Liaoning 116024, China \\ ${ }^{2}$ Faculty of Infrastructure Engineering, Dalian University of Technology, Dalian, Liaoning 116024, China \\ Correspondence should be addressed to Shichun Chi; schchi@dlut.edu.cn
}

Received 28 January 2019; Revised 17 April 2019; Accepted 30 April 2019; Published 20 May 2019

Academic Editor: Giovanni Garcea

Copyright (C) 2019 Yunfei Xie and Shichun Chi. This is an open access article distributed under the Creative Commons Attribution License, which permits unrestricted use, distribution, and reproduction in any medium, provided the original work is properly cited.

\begin{abstract}
Important buildings such as nuclear power plants always require stricter control of differential settlement than ordinary buildings. Therefore, it is necessary to provide an optimized design for the piled raft foundations of important buildings. In this paper, a new optimization method (using different pile diameters and different pile spacing) was proposed for the design of piled raft foundations. This method adjusts the pile diameters and pile spacing according to the stress distribution at the pile top of the initial design to achieve a more uniform settlement of the raft and stress distribution on top of piles, which can solve the differential settlement problems caused by uneven loads of the superstructure. After optimized design, the differential settlement and integral bending moment of the raft decreased more than $64 \%$ and $52 \%$, respectively, and the differential stress on top of piles decreased by at least $63 \%$. The new method proposed in this paper could be applied to large-scale piled raft foundations with complex superstructure loads.
\end{abstract}

\section{Introduction}

Rigid foundations are a good choice for important buildings to resist static loads and seismic loads, but the rigid foundations are always limited. Piled raft foundations (PRFs) have been widely adopted in the design of high-rise buildings and important buildings in recent years due to their efficiency in controlling the total settlement and differential settlement and their high bearing capacity [1]. However, the differential settlement of the PRF designed by the conventional method for ordinary buildings may not satisfy the requirements of important buildings. The piles are usually uniformly arranged in conventional PRF designs, that is, a consistent pile diameter, length, and spacing. Several studies have shown that even if the load is uniform, the peripheral piles either carry a greater proportion of the load than the central piles under a rigid cap or suffer from a flexible cap which exhibits differential settlement due to pilesoil-raft interactions [2-10], and nonuniform loading can exacerbate these problems. Padfield and Sharrock [11] briefly introduced a method of enhancing pile group performance by varying the pile geometries across the group. Truman and Hoback [12] proposed a combined finite element (FE) and optimization technique to minimize the system-wide distortion of PRFs. Using a centrifuge model test and an extensive parametric study, Randolph [13] and Nguyen et al. [14] verified that differential settlement could be effectively reduced by adding several piles in the center of a raft. These researchers stated that the differential settlement could be minimized by placing "stronger" piles in the center than in the periphery of the raft. Kim et al. [15] studied the optimal location of piles in a PRF using genetic algorithms (GAs) under the assumption of linear elastic pilesoil interactions.

An optimized design method based on the stress distribution at the pile top (or BSDPT optimization method for short) is presented in this paper; this method adjusts the pile diameters and pile spacing according to the stress distribution at the pile top to achieve a more uniform settlement and stress distribution at the pile top. During the 
optimization process, the top loads of the piles will not exceed their ultimate bearing capacities, and the change in the total pile material after optimized design will remain within $1 \%$ of the initial design [16], allowing for easy comparison. The piles in this PRF are friction piles, for which the bearing capacity is mainly provided by the friction between the piles and the soil. During calculation, the nonlinear elasticity of the soil and soil-raft-pile interaction are considered. A 3D finite element model (FEM) of the PRF from a nuclear power plant was established. After optimizing the design, the differential settlement and the differential stress on top of the pile group and the maximum integral bending moment of the raft all decrease more than $50 \%$, which allows an optimal and economical raft-pile system to be obtained without the need for complex iterative computations.

\section{Optimization Method}

Recently, the characteristics of piled rafts were investigated by performing tests of model rafts resting on pile-reinforced sand [17] and centrifuge experiments [18] with small-scale models. There has been substantial agreement between such experimental measurements and the outcomes of simplified numerical analyses [9, 19]. Nguyen et al. [1] performed a parametric study using PLAXIS 3D, and its validity was confirmed via centrifuge model tests. This study demonstrated that a concentrated pile arrangement can considerably reduce the total settlement, differential settlement, and bending moments of the raft; moreover, the effects of various parameters, such as the pile length, pile number, and raft thickness, on the behavior of the piled raft were also investigated. Sinha and Hanna [20] investigated the effects of pile diameter and pile spacing on PRF. The conclusions of these studies are presented in Table 1.

With these rules, engineers can achieve an optimal design with "dissimilar piles." However, the rules in Table 1 are empirical conclusions without a clear mathematical relationship, which will affect the efficiency of the optimized design. Thus, other researchers [16, 21-25] have sought to combine an optimization function with numerical calculations to solve this problem and obtain good results.

The aforementioned optimization methods can be divided into two main categories: empirical optimization methods and mathematical optimization methods. Empirical optimization methods are mainly based on experience or the analysis of a large number of numerical models, summarization of the empirical coefficient, and application to practical engineering. However, using these empirical coefficients is not convenient enough, good optimization results require multiple trial calculations, and this will hinder the application of the method. Mathematical optimization methods can solve the problems through a combination of mathematical tools and numerical methods; therefore, accurate optimal results can be obtained, but it is difficult for ordinary engineers to learn. The main idea of the BSDPT optimization method proposed in this paper is to reduce the differential settlement through adjusting the pile diameters and spacing according to the stress distribution on top of the pile group.

The flow chart of the BSDPT optimization method is shown in Figure 1, and the detailed description is shown as follows:

(1) Step 1: the initial design of the PRF is completed. The PRF is designed by the traditional design method, with a consistent pile length, pile diameter, and pile spacing.

(2) Step 2 (FEM calculation): a 3D FE model is established using ANSYS software. The load is the selfweight of PRF and superstructure. The load is divided into several load steps to consider the nonlinearity of the soil and the construction process of the superstructure.

(3) Step 3: pile diameters through the extreme pile top stresses are adjusted. The aim of the BSDPT optimization method is to reduce the pile top stresses that are greater than $\sigma_{a}$ and increase the pile top stresses that are less than $\sigma_{a}$ to make the pile top stresses and settlements more uniform. It is assumed that the diameter and top stress of pile $i$ of the initial design and optimized design satisfy the following relationship:

$$
\frac{d_{i}^{\prime}}{d_{i}}=\frac{\sigma_{i}}{\sigma_{i}^{\prime}},
$$

where

$\sigma_{i}^{\prime}=\sigma_{i}-\frac{\left(\sigma_{i}-\sigma_{j}\right)}{2},\left\{\begin{array}{l}\text { if, } \sigma_{i}=\sigma_{i, \max }, \text { then, } \sigma_{j}=\sigma_{j,-}, \\ \text { if, } \sigma_{i}=\sigma_{i, \min }, \text { then, } \sigma_{j}=\sigma_{j,+},\end{array}\right.$

$d$ and $d_{i}^{\prime}$ are the diameters of pile $i$ before and after optimization, respectively; $\sigma_{i}$ is the stress on top of pile $i ; \sigma_{i, \max }, \sigma_{i, \min }$, and $\sigma_{a}$ are the maximum, minimum, and average pile top stresses of initial design, respectively. $\sigma_{j,-}=\sigma_{a}-25 \% \times\left(\sigma_{a}-\sigma_{i, \min }\right)$ and $\sigma_{j,+}=\sigma_{a}+25 \% \times\left(\sigma_{i, \max }-\sigma_{a}\right)$ are the characteristic stress points. All the characteristic stress points and stress partitions are shown in Figure 2.

(4) Step 4: the piles according to the pile top stresses are grouped. The piles are divided into 5 subgroups according to the left side of equation (3); each pile subgroup has the same diameter, and their corresponding adjusted pile diameters are shown in equation (3), which are calculated through characteristic stresses using equations (1) and (2). During this process, it ensured that the total material change in the piles does not exceed 1\%. Fine-tuning can be performed on the pile diameters at the junction of adjacent groups. Finally, a new pile group scheme (scheme 1) with different pile diameters can be obtained: 
TABLE 1: The relationships between the parameters of the PRF.

\begin{tabular}{|c|c|c|c|c|}
\hline Result & Raft thickness & Pile length & Pile diameter & Pile distance \\
\hline Total settlement & 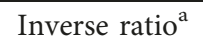 & Inverse ratio & Inverse ratio & Little effect \\
\hline Differential settlement & Inverse ratio & Inverse ratio & Inverse ratio & Direct ratio \\
\hline Bending moments of the raft & Direct ratio $^{\mathrm{b}}$ & Little effect ${ }^{c}$ & Inverse ratio & Direct ratio \\
\hline
\end{tabular}

${ }^{a}$ The calculation result decreases as the variable increases. ${ }^{\text {b}}$ The calculation result increases with an increase in the variable. ${ }^{\mathrm{c}}$ The variables have only a slight effect on the calculations.

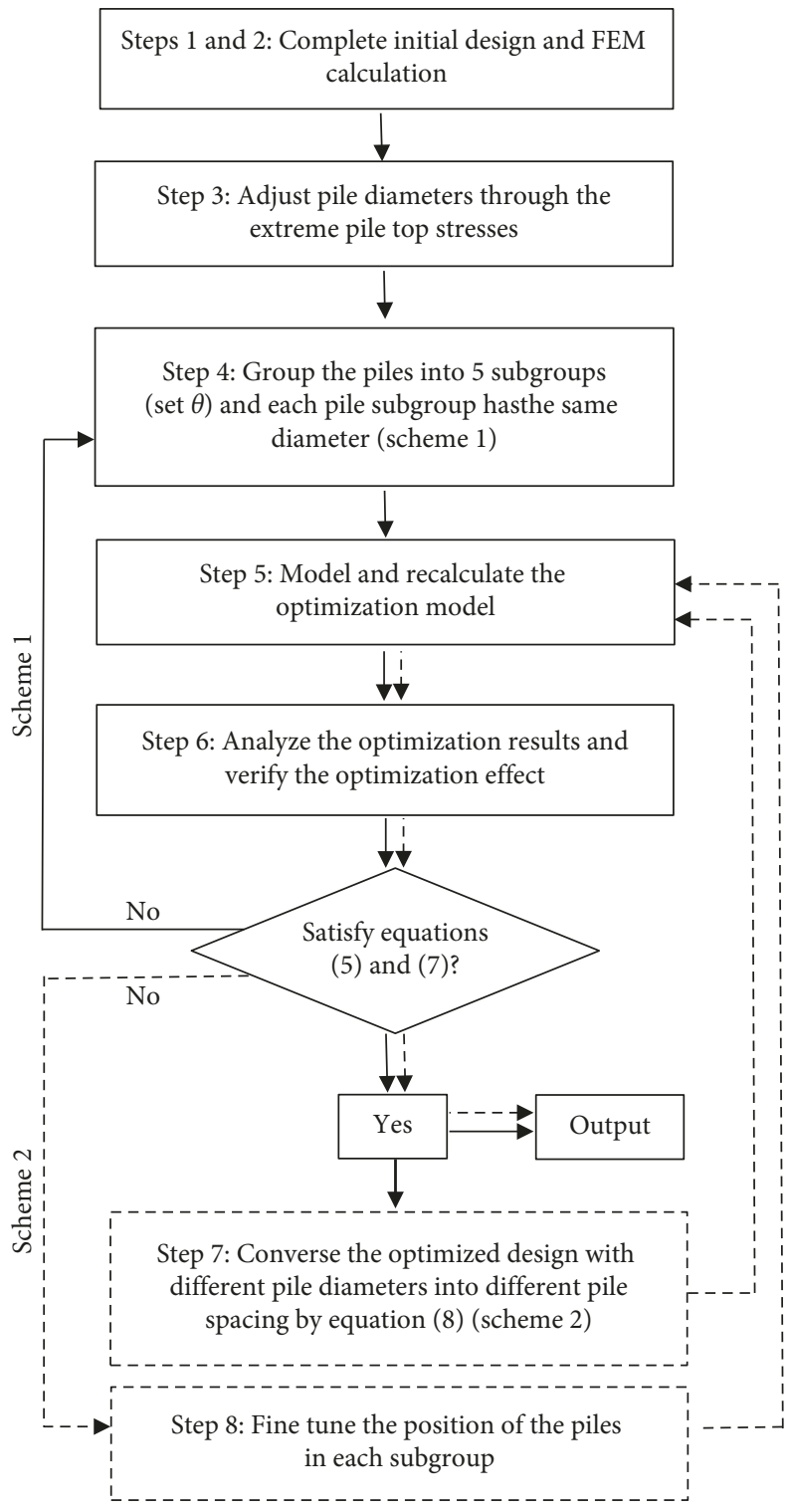

FIgUre 1: The flow chart of the BSDPT optimization method.

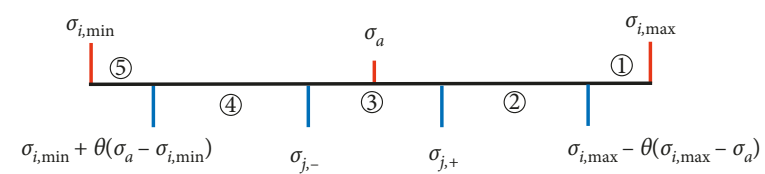

Figure 2: Characteristic stress points and stress partitions. 
$\begin{cases}\sigma_{i, \max }-\theta \times\left(\sigma_{i, \max }-\sigma_{a}\right) \leq \sigma \leq \sigma_{i, \max } & \longrightarrow(G 1), \\ \sigma_{j,+} \leq \sigma \leq \sigma_{i, \max }-\theta \times\left(\sigma_{i, \max }-\sigma_{a}\right) & \longrightarrow(G 2), \\ \sigma_{j,-} \leq \sigma \leq \sigma_{j,+} & \longrightarrow(G 3), \\ \sigma_{i, \min }+\theta \times\left(\sigma_{a}-\sigma_{i, \min }\right) \leq \sigma \leq \sigma_{j,-} & \longrightarrow(G 4), \\ \sigma_{i, \min } \leq \sigma \leq \sigma_{i, \min }+\theta \times\left(\sigma_{a}-\sigma_{i, \min }\right) & \longrightarrow(G 5),\end{cases}$

where $\theta$ is a parameter to control the range of each subgroup, and $0<\theta<0.5$.

(5) Step 5: the optimized model is recalculated.

(6) Step 6: the optimization results are analyzed, and the optimization effect is verified. The settlements of the raft and the stresses on top of the piles can be obtained. $F$ represents the optimization rate and is defined as

$$
F=\frac{R-R^{\prime}}{R}
$$

where $R$ and $R^{\prime}$ are the variables of the initial design and the optimized design, respectively; these variables include the differential settlement and integral bending moment of the raft and the differential stress on top of the piles. The main aim of this optimization method is to reduce the differential settlement: the corresponding optimization function and the constraints are shown in equations (5) and (6):

$$
50 \% \leq F\left(S_{\Delta}, S_{\Delta}^{\prime}\right) \leq 100 \% .
$$

Such that

$$
\begin{aligned}
\left|\frac{V-V^{\prime}}{V}\right| & \leq 1 \%, \\
p_{i} & \leq p_{i, u}, \quad i=1,2, \ldots, n,
\end{aligned}
$$

where $S_{\Delta}$ and $S_{\Delta}^{\prime}$ are the differential settlements before and after optimized design; $p_{i}$ is the load on top pile $i, p_{i, u}$ is the ultimate bearing capacity of pile $i, n$ is the total number of piles in the PRF, and $V$ and $V^{\prime}$ are the total volumes of the piles before and after optimized design. If equation (5) is not satisfied, then $\theta$ is adjusted, and steps $4-6$ are repeated; if any pile does not satisfy equation (7), its diameter will be changed to a neighboring diameter which is bigger than it.

(7) Step 7: the optimized design with different pile diameters is converted into that with different pile spacing using equation (8):

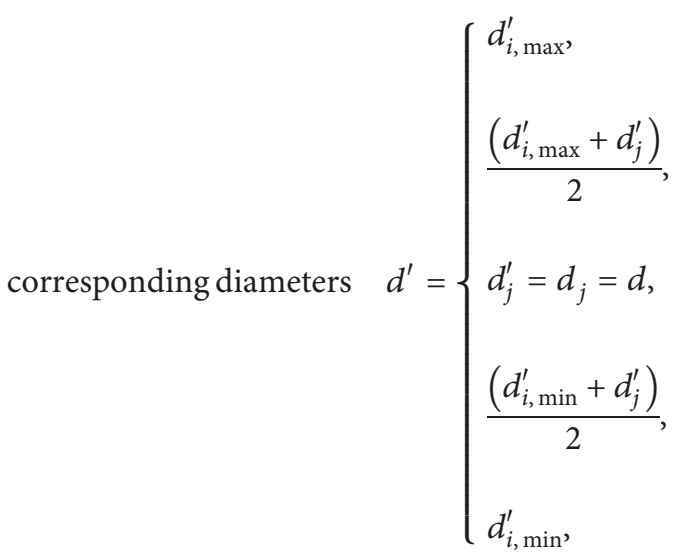

$$
N_{i} A_{i}=N_{i}^{\prime} A_{i}^{\prime}, \quad i=1,2,3,4,5,
$$

where $N_{i}$ is the number of piles in subgroup $i, A_{i}$ is the section area of a pile in this subgroup, and $N_{i}^{\prime}$ and $A_{i}^{\prime}$ are the corresponding variables after optimization. During this process, if the total number of piles is not equal to that of the initial design, the pile numbers in each subgroup are fine tuned for consistency. The piles in each subgroup are evenly arranged. Finally, a pile foundation scheme (scheme 2) with different pile spacing can be obtained.

(8) Step 8: if the optimization objective is not satisfied, fine tune the positions of the piles in each subgroup, and go back to step 5. It is difficult to assign the piles to the exact location in an irregular range, especially near the junction of different subgroups. If the force at the top of the pile exceeds its own ultimate bearing capacity, then reduce the spacing of the surrounding piles until the force at the top of the pile is less than its ultimate bearing capacity.

\section{Model Validation}

Before the simulation of the PRF, a single pile test from Jiang [26] is simulated to verify the feasibility of the material constitutive model, boundary conditions, parameter selection, and FE method used in this paper. All the numerical analyses were performed using the commercial code ANSYS.

3.1. Numerical Model. The model consists of a pile (with a circular cross section, a diameter of $2.8 \mathrm{~m}$ and a depth of $125 \mathrm{~m}$, for which the pile length between $+4 \mathrm{~m}$ and $-46 \mathrm{~m}$ is not in the soil) and a soil model with a diameter of $100 \mathrm{~m}$ and a depth of $174 \mathrm{~m}$. The soil model is composed of nine layers (Figure 3). The soil and the concrete (pile) are modeled with SOLID45 elements from the ANSYS database, which are 8node $3 \mathrm{D}$ elements. Although these elements may not be appropriate for bending, they can adequately model the shear deformation of the soil [27]. The maximum size of the pile element and the minimum size of the soil element are $1 \mathrm{~m}$, and the maximum size of the soil element is $5 \mathrm{~m}$. The final numbers of elements and nodes are 18676 and 21775, respectively. Nodes are shared along the pile-soil interfaces, 


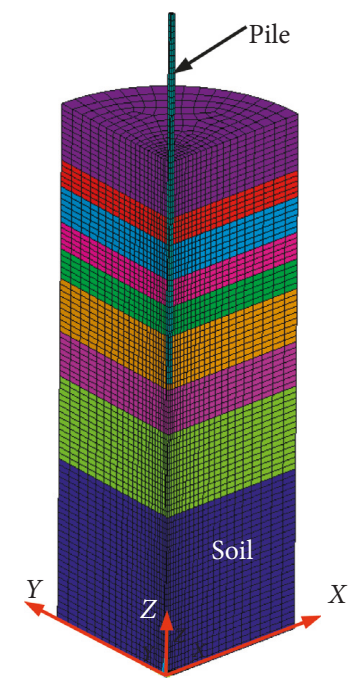

Figure 3: A single pile model.

zero slippage at these interfaces is assumed. To simplify the computational model, only a quarter of the actual model was modeled due to its symmetry.

3.2. Material Model Parameters. The material of the pile model is considered to be reinforced concrete with Young's modulus of $E=33 \mathrm{GPa}$, an effective unit weight of $\gamma=1400 \mathrm{kN} / \mathrm{m}^{3}$, and Poisson's ratio of $\nu=0.167$. The concrete pile is modeled using an elastic constitutive model. The soil layers are modeled using a Duncan-Chang (DC) model, which is an incremental nonlinear (hyperbolic) stressdependent model based on Hooke's Law, the main feature of which is described by the nonlinear relationship between stress and strain; the tangent modulus and Poisson's ratio are expressed in incremental relationships. Initial Young's modulus for each soil layer is obtained via the DC model using the initial principal stresses $\left(\sigma_{1}\right.$ and $\sigma_{3}$ ), where the principal initial stresses of each element are obtained from equation (9), $z$ is the depth of the element center to the ground, $K_{0}$ is the static lateral pressure coefficient, and $\gamma$ is the gravity per unit volume of the soil:

$$
\left\{\begin{array}{l}
\sigma_{1}=\gamma z, \\
\sigma_{3}=K_{0} \gamma z, \quad K_{0}=0.95-\sin \varphi .
\end{array}\right.
$$

A detailed description of the DC model can be found in Chen et al. [28] and Duncan and Chang [29]. The DC model adopted in this paper specifies 8 parameters $\left(K, n, \varphi, c, R_{\mathrm{f}}, G\right.$, $F$, and $D$ ), as listed in Table 2 .

3.3. Boundary Conditions and Loading. The following boundary conditions were applied in the computational model:

(1) All of the nodes at the bottom (with a $Z$ coordinate of $-174 \mathrm{~m}$ ) were constrained; i.e., the translational displacements in the nodal $X, Y$, and $Z$ directions are equal to zero.
(2) Symmetry is considered in the lateral areas of the model $(X=0 \mathrm{~m}$ and $Y=0 \mathrm{~m})$. The displacement along the side of the curved surface is fixed in the $X$ or $Y$ directions; i.e., the displacement in the $Y$ direction on the $Y=0$ section is zero and the displacement in the $X$ direction on the $X=0$ section is zero.

The load on top of the pile is $5 \mathrm{MPa}$, which is divided into 20 stages of loading, increasing from $0 \mathrm{MPa}$ to $5 \mathrm{MPa}$ with an increment of $0.25 \mathrm{MPa}$.

3.4. Results and Validation. The load-settlement curve of the single pile is presented in Figure 4, where the pile load test results from the study by Jiang [26] and the simulation result from this paper (ANSYS-3D model) are compared. The detailed data regarding the ultimate load and corresponding pile top settlement in Figure 4 are listed in Table 3. The results indicate that the simulation result is in good agreement with the experimental results. Therefore, the FE method adopted in this paper can simulate the stress state of the pile before its ultimate bearing capacity. Before the load reaches the ultimate load, the pile does not undergo a sharp subsidence; i.e., the interface slippage between the pile and soil is not severe. Therefore, unless the pile top load exceeds the ultimate bearing capacity, the rigid contact assumption between the pile and soil is valid.

\section{Determination and Verification of the Ultimate Bearing Capacity of Different Piles}

The proposed BSDPT optimization method presented that during the optimization process, the pile top load cannot exceed its ultimate bearing capacity. For the piles which did not have the single pile load test, the corresponding ultimate bearing capacity can be estimated by empirical formulas, such as the empirical formulas (equation (10)) from the Chinese code [30]:

$$
\mathrm{Q}_{\mathrm{uk}}=u \sum \psi_{\mathrm{si}} q_{\mathrm{sik}} l_{i}+\psi_{\mathrm{p}} q_{\mathrm{pk}} A_{\mathrm{p}}
$$

where $Q_{u k}$ is the ultimate bearing capacity of a single pile; $u$ is the circumference of the pile; $A_{\mathrm{p}}$ is the cross-sectional area of the pile tip; $l_{\mathrm{i}}$ is the thickness of the $i_{\text {th }}$ soil layer around the pile; $q_{\text {sik }}$ and $q_{\mathrm{pk}}$ are the ultimate shaft resistance and the ultimate tip resistance of the $i_{\text {th }}$ soil layer around the pile, respectively; and $\psi_{\mathrm{si}}$ and $\psi_{\mathrm{p}}$ are the size effect coefficients of shaft resistance and tip resistance of large diameter (diameter greater than $0.8 \mathrm{~m}$ ) piles, respectively.

During the estimation process, it is difficult to determine the values of $q_{\text {sik }}$ and $q_{\mathrm{pk}}$ in different layer soils because the values provided in the code [30] are given as ranges. Therefore, the ultimate bearing capacity from the pile load test [26] is used to verify its estimated value and the soil parameters. Table 4 reports the soil types and relevant parameters for each soil layer, which will be used in equation (10). Table 5 lists the field test value and empirical value of the ultimate bearing capacity of the pile with a diameter equal to $2.8 \mathrm{~m}$. $2 \%$ error between the results indicates that 
TABLe 2: Parameters of the DC model used in this paper.

\begin{tabular}{|c|c|c|c|c|c|c|c|c|c|c|c|c|c|}
\hline \multirow{2}{*}{ Soil } & \multicolumn{2}{|c|}{ High level (m) } & \multirow{2}{*}{ Type } & \multirow{2}{*}{$R_{\mathrm{f}}$} & \multirow{2}{*}{$k$} & \multirow{2}{*}{$n$} & \multirow{2}{*}{$G$} & \multirow{2}{*}{$F$} & \multirow{2}{*}{$D$} & \multirow{2}{*}{$k_{\mathrm{ur}}$} & \multirow{2}{*}{$\varphi\left({ }^{\circ}\right)$} & \multirow{2}{*}{$c(\mathrm{kPa})$} & \multirow{2}{*}{$\rho_{s}\left(\mathrm{~g} / \mathrm{cm}^{3}\right)$} \\
\hline & Single pile model & PRF model & & & & & & & & & & & \\
\hline 1 & $-65 \sim-46$ & $18.44 \sim 27$ & Fine & 0.84 & 640 & 0.59 & 0.40 & 0 & 0 & 970 & 37.1 & 14.7 & 1.09 \\
\hline 2 & $-74 \sim-65$ & $15 \sim 18.44$ & Fine sand & 0.84 & 670 & 0.59 & 0.40 & 0 & 0 & 1010 & 38.2 & 15.5 & 1.11 \\
\hline 3 & $-86 \sim-74$ & $13 \sim 15$ & Medium-coarse gravel & 0.80 & 520 & 0.56 & 0.40 & 0 & 0 & 780 & 34.9 & 11.7 & 1.15 \\
\hline 4 & $-95 \sim-86$ & $2 \sim 13$ & Medium-coarse sand & 0.70 & 460 & 0.52 & 0.40 & 0 & 0 & 700 & 34.6 & 10.8 & 1.09 \\
\hline 5 & $-105 \sim-95$ & $-4 \sim 2$ & Medium-coarse gravel & 0.80 & 500 & 0.58 & 0.40 & 0 & 0 & 760 & 38.1 & 16.5 & 1.15 \\
\hline 6 & $-123 \sim-105$ & $-17 \sim-4$ & Fine sand & 0.91 & 430 & 0.62 & 0.40 & 0 & 0 & 660 & 34.6 & 15.7 & 1.10 \\
\hline 7 & $-138 \sim-123$ & $-21 \sim-17$ & Medium-coarse gravel & 0.80 & 570 & 0.59 & 0.40 & 0 & 0 & 900 & 34.2 & 19.9 & 1.10 \\
\hline 8 & $-166 \sim-138$ & - & Clay & 0.78 & 370 & 0.52 & 0.38 & 0 & 0 & 500 & 28.5 & 72.7 & 1.03 \\
\hline 9 & $-220 \sim-166$ & - & Silty fine sand & 0.78 & 450 & 0.57 & 0.40 & 0 & 0 & 700 & 32.0 & 42 & 1.06 \\
\hline
\end{tabular}

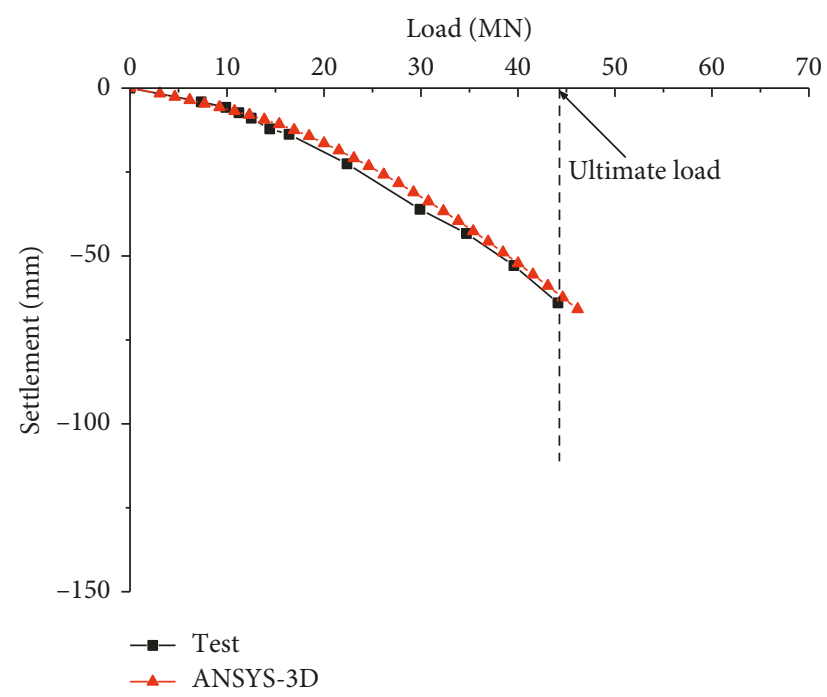

FIgURE 4: Comparison of load-settlement curves between the FEM and pile load test.

TABLE 3: Comparison of the results at the ultimate load.

\begin{tabular}{lcc}
\hline Name & Field test value & Analysis value by ANSYS-3D (this paper) \\
\hline Ultimate bearing capacity $(\mathrm{MN})$ & 44.66 & 44.66 \\
Displacement $(\mathrm{mm})$ & 64.67 & 64.84 \\
\hline
\end{tabular}

TABLE 4: Relevant parameters of the soil layers surrounding piles.

\begin{tabular}{|c|c|c|c|c|c|c|c|}
\hline \multirow{2}{*}{ Soil layer $i$} & \multirow{2}{*}{ Soil types } & \multirow{2}{*}{$q_{\text {sik }}(\mathrm{kPa})$} & \multirow{2}{*}{$q_{\mathrm{pk}}(\mathrm{kPa})$} & \multirow[b]{2}{*}{$\psi_{\mathrm{si}}$} & \multirow[b]{2}{*}{$\psi_{\mathrm{p}}$} & \multicolumn{2}{|c|}{$l_{i}(\mathrm{~m})$} \\
\hline & & & & & & $d=2.8 \mathrm{~m}$ & $d=1.3 \mathrm{~m}-1.7 \mathrm{~m}$ \\
\hline 1 & Fine sand & 60 & - & $(0.8 / d)^{1 / 3}$ & $(0.8 / d)^{1 / 3}$ & 19 & - \\
\hline 2 & Fine sand & 70 & - & $(0.8 / d)^{1 / 3}$ & $(0.8 / d)^{1 / 3}$ & 9 & 3 \\
\hline 3 & Medium-coarse gravel & 110 & - & $(0.8 / d)^{1 / 3}$ & $(0.8 / d)^{1 / 3}$ & 12 & 2 \\
\hline 4 & Medium-coarse sand & 100 & - & $(0.8 / d)^{1 / 3}$ & $(0.8 / d)^{1 / 3}$ & 9 & 11 \\
\hline 5 & Medium-coarse gravel & 120 & - & $(0.8 / d)^{1 / 3}$ & $(0.8 / d)^{1 / 3}$ & 10 & 6 \\
\hline 6 & Fine sand & 80 & 1500 & $(0.8 / d)^{1 / 3}$ & $(0.8 / d)^{1 / 3}$ & 16 & 13 \\
\hline 7 & Medium-coarse gravel & 120 & 2600 & $(0.8 / d)^{1 / 3}$ & $(0.8 / d)^{1 / 3}$ & - & 2 \\
\hline
\end{tabular}

Note. The tip resistance of different soil types is the lower limit of the corresponding range in China code [30]. 
TABLE 5: Ultimate bearing capacity of single piles with different pile diameters and lengths.

\begin{tabular}{|c|c|c|c|c|c|c|}
\hline Ultimate bearing capacity of a single pile & $\begin{array}{l}d=2.8 \mathrm{~m} \\
(l=75 \mathrm{~m})\end{array}$ & $\begin{array}{l}d=1.3 \mathrm{~m} \\
(l=37 \mathrm{~m})\end{array}$ & $\begin{array}{l}d=1.4 \mathrm{~m} \\
(l=37 \mathrm{~m})\end{array}$ & $\begin{array}{l}d=1.5 \mathrm{~m} \\
(l=37 \mathrm{~m})\end{array}$ & $\begin{array}{l}d=1.6 \mathrm{~m} \\
(l=37 \mathrm{~m})\end{array}$ & $\begin{array}{l}d=1.7 \mathrm{~m} \\
(l=37 \mathrm{~m})\end{array}$ \\
\hline Field test value $^{\mathrm{a}}(\mathrm{MN})$ & $44.7^{\mathrm{c}}$ & - & - & - & - & - \\
\hline Empirical value $^{\mathrm{b}}(\mathrm{MN})$ & 43.6 & 15.2 & 16.2 & 17.2 & 18.2 & 19.2 \\
\hline
\end{tabular}

${ }^{a}$ The field test value is obtained through a single pile bearing capacity test. ${ }^{b}$ The empirical value is calculated by equation (10). ${ }^{c}$ Field test value is from Jiang [26].

the empirical parameters of the soils in Table 4 are well suited. With these empirical parameters, the ultimate bearing capacity of the piles which have different diameters and lengths but have the same surrounding soil properties can be estimated in the same manner, as indicated in Table 5 .

\section{PRF FEM and Simulation Analysis}

The PRF model adopted in this study originates from a nuclear power plant. There are two reasons for this choice. Firstly, considering the importance of the nuclear power plant, it is necessary to design a high-demand pile foundation. Secondly, the complex superstructure of the nuclear power plant often result in uneven loads on the raft and the irregular pile group shape, which makes the selection of this model more representative.

5.1. Soil and Piled Raft Simulation. The PRF FE model is shown in Figure 5. The model contains 7 layers of soil and one layer of bedrock and the thicknesses of the soil layers are reported in Table 2. The calculation range of the soil in horizontal direction is approximately 3 times the length of the raft and the bottom boundary of the model is located $5 \mathrm{~m}$ below the top of the bedrock. According to the initial design, 211 friction piles with a diameter of $1.5 \mathrm{~m}$ and a length of $37 \mathrm{~m}$ are used, and the spacing between the piles is approximately $4 \mathrm{~m}$. The thickness, length, and width of the raft are $1.8 \mathrm{~m}, 78 \mathrm{~m}$, and $53 \mathrm{~m}$, respectively. The material parameters of the raft, pile, and bedrock are presented in Table 6.

5.2. Superstructure Loads. Because the soil DC model is an incremental nonlinear stress-dependent model, the increment value of each load step affects the accuracy of the results. The load history and the distribution of the load acting on the raft are two key factors. The weight of the superstructure is the main load, which has been divided into 19 load steps to consider the influence of the load history. Each load step is considered to be a surface load acting on the raft, the location and the distribution shape of the load are based on the superstructure. A sketch of the superstructure and the load steps are shown in Figure 6(a), and the distribution shape and the location of each load step are shown in Figure 6(b). The order of these load steps is determined according to the construction sequence.

5.3. Boundary Conditions and Model Details. The following boundary conditions are applied in the PRF model:
(1) All soil nodes at the lowest elevation (with a $Z$ coordinate of $-26 \mathrm{~m}$ ) are considered to be constrained in three directions, i.e., the translations in the nodal $X, Y$, and $Z$ directions are equal to zero

(2) The outermost lateral boundary nodes have only vertical displacement, and the motion in the two horizontal directions is constrained

The elements used in this model are solid elements, and full integration is used. The maximum element size in horizontal and vertical directions is $6 \mathrm{~m}$ and $3 \mathrm{~m}$. The horizontal length of a pile element is half of the pile diameter. The total numbers of soil elements and associated nodes are 261,000 and 275,000 , respectively.

5.4. Analysis Procedure. There are 20 load steps during the analysis procedure. The gravity of the soil $(i=1)$ is the first step, and the gravity loading from the superstructure is divided into 19 steps (step $i$ from 2 to 20) to simulate the load during the construction process (Figure 6). The stress state is the output at the end of each calculation step for each load step and is used to calculate the elastic modulus and Poisson's ratio for the next step via the DC model.

5.5. Results of the Initial Design. Figure 7 shows the contour lines of the raft settlement and the vertical stress distribution on top of the piles in the initial design. The maximum pile top stress in the pile group is $7.1 \mathrm{MPa}(12.5 \mathrm{MN})$, which did not exceed its ultimate bearing capacity of $17.2 \mathrm{MN}$, as indicated in Table 5. All the raft subsidence contours present an irregular ring-like shape, and as the distance from the center increases, the raft subsidence gradually decreases. The maximum settlement of the raft is $0.048 \mathrm{~m}$, which occurred in the center of the raft. The nonuniform distribution of the load on the raft and the pile-soil interactions are the main reasons. A comparison of these results with those of similar analyses $[1,18]$, especially those based on similarly sized models [31-33], indicates that the trend of the settlement contour line is in accordance with normal trends, reflecting the characteristics of the soil-pile interaction and the complex loading forms of the superstructure.

\section{Optimized Design of the Large PRF}

\subsection{Optimized Design under Various Pile Diameters}

6.1.1. Procedure of the Optimized Design. Following the BSDPT optimization method (steps 3 to 6 ), the pile top stress of initial design was obtained in Figure $7(\mathrm{~b})$. The average stress $\left(\sigma_{a}\right)$ on top of the piles is $6 \mathrm{MPa}, \sigma_{i, \max }=7.1 \mathrm{MPa}$, and 


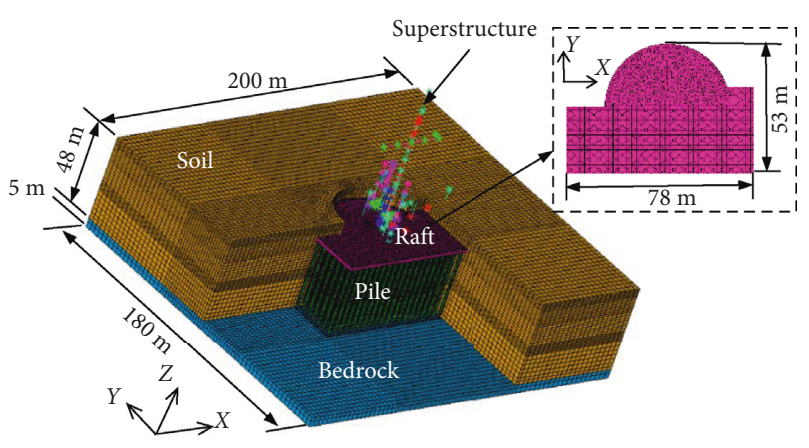

(a)

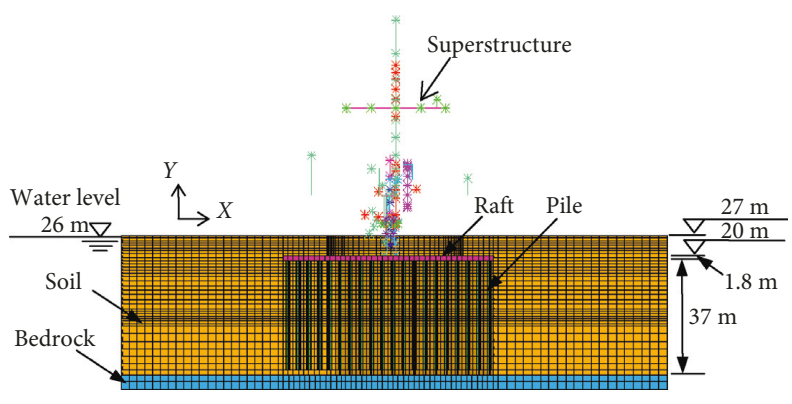

(b)

FiguRE 5: 3D view of the nuclear power plant system: (a) the components and peripheral dimensions of the model; (b) cross-sectional view of the model.

Table 6: Calculated parameters of the pile, raft, and bedrock.

\begin{tabular}{lccc}
\hline Property & Elastic modulus $(\mathrm{Pa})$ & Poisson's ratio & Density $\left(\mathrm{kg} / \mathrm{m}^{3}\right)$ \\
\hline Pile & $3.0 \times 10^{10}$ & 0.17 & 2400 \\
Raft & $2.0 \times 10^{10}$ & 0.17 & 2400 \\
Bedrock & $1.5 \times 10^{10}$ & 0.28 & 2450 \\
\hline
\end{tabular}

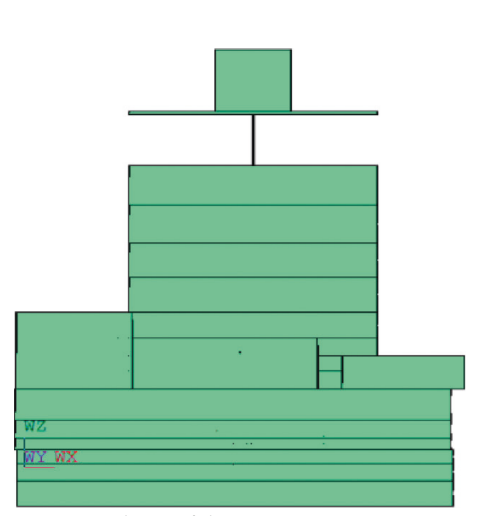

Shape of the superstructure

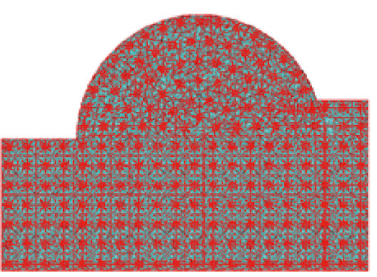

Steps 2 to 11

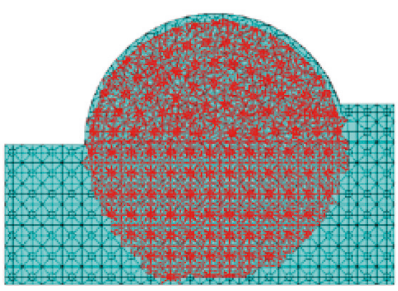

Steps 14 to 18

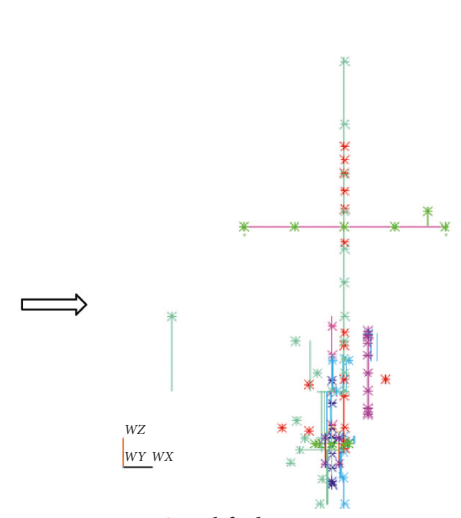

Simplified superstructure

a)

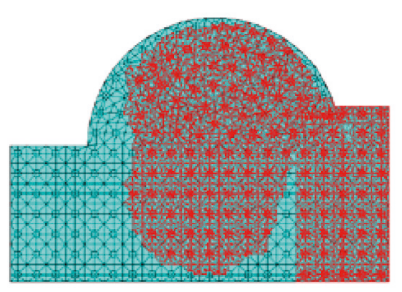

Step 12

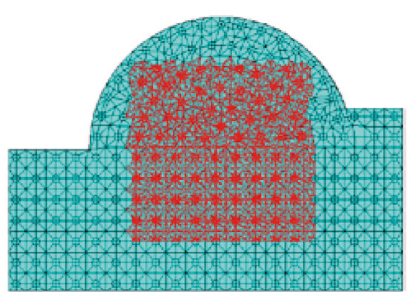

Steps 19 to 20

(b)

FIGURE 6: Superstructure of this system and corresponding simplified load: (a) the shape of the superstructure and the value of each load step; (b) the shape of each surface load that acts on the raft. 


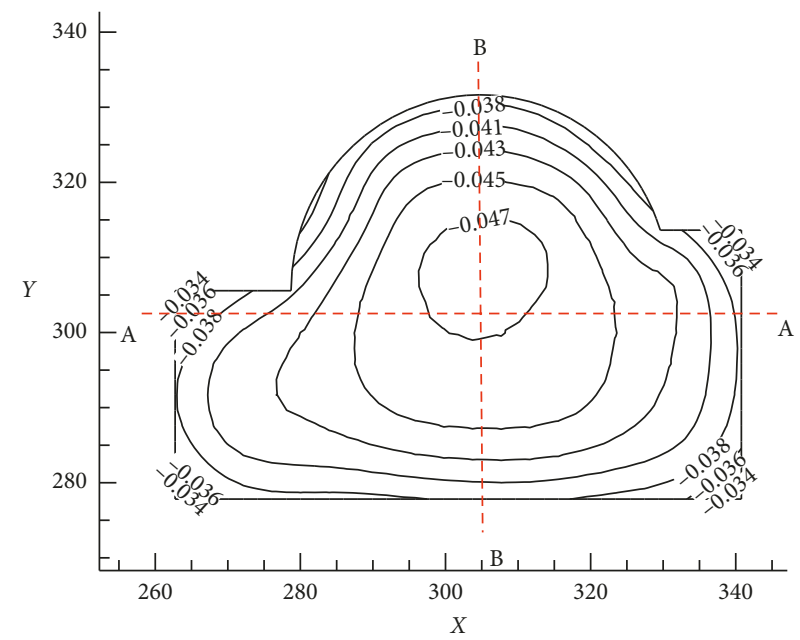

(a)

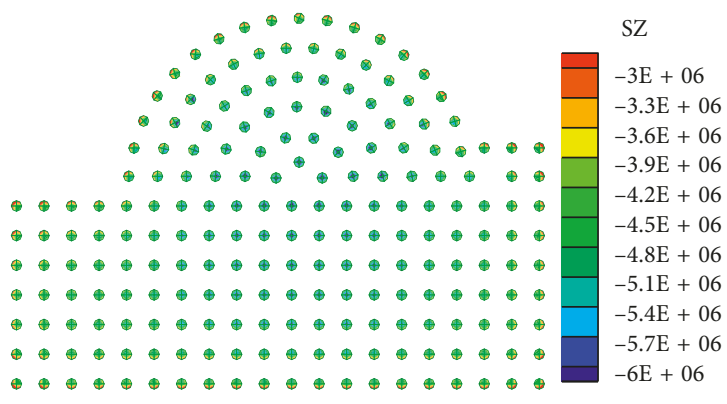

(b)

Figure 7: The result of the initial design: (a) initial settlement on top of the piled raft (m); (b) vertical stress on top of the pile groups (Pa).

$\sigma_{i, \min }=4.7 \mathrm{MPa}$. Substituting $\sigma_{a}, \sigma_{i, \max }$, and $\sigma_{i, \min }$ into equations (1)-(3), $d_{i, \max }$ and $d_{i, \min }$ can be obtained, and these details are provided in Table 7 . Equation (11) gives the range of the five subgroups with $\theta=0.25$, and the corresponding diameters are reported in Table 7:

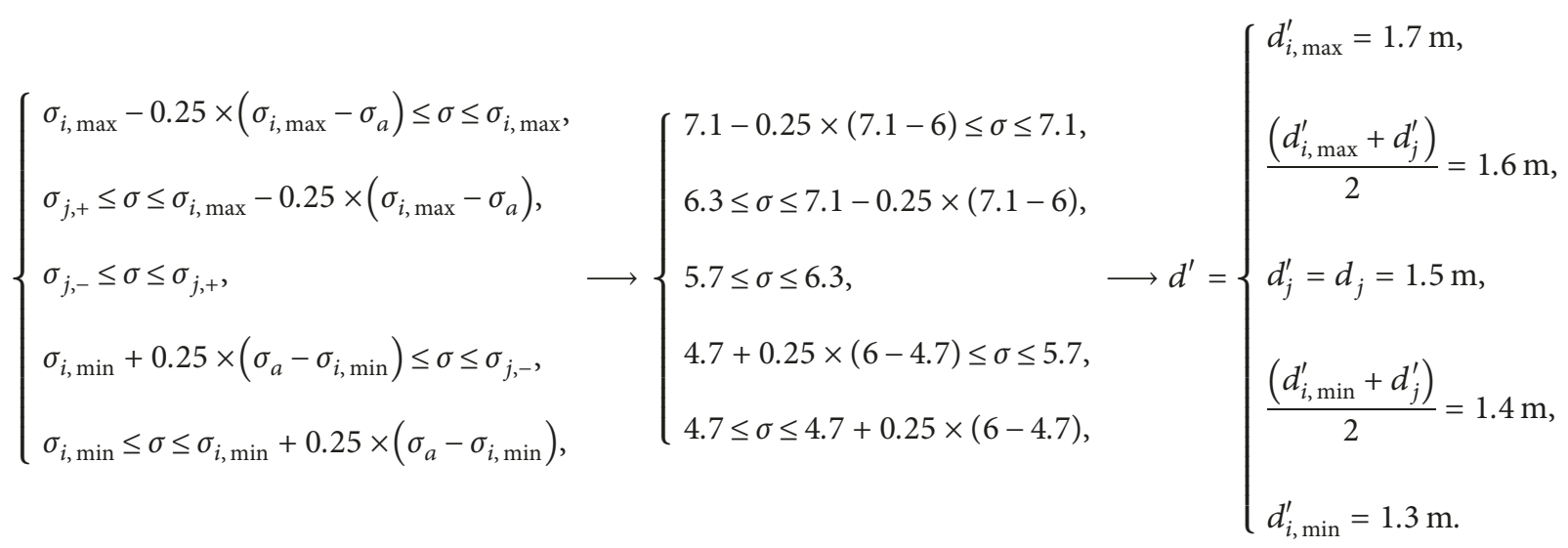

Most of the differential settlements and differential stresses disappeared when $\theta=0.25$, and the optimization objectives and the constraints in step 6 are simultaneously satisfied. Figure 8 shows the final pile arrangement after optimization, with the total pile material increasing by $0.1 \%$ compared with that of the initial design.

\subsubsection{FEM Calculated Results after Diameter Optimization.} Figure 9 presents the settlement contours on top of the raft in scheme 1. A comparison of Figures $7(a)$ and 9 demonstrates that the settlement contour of the raft becomes more uniform than the initial design after the optimized design. The maximum load on top of the piles with different diameters is reported in Table 8. Compared with the ultimate bearing capacity determined by empirical formula (10), no pile exceeds its ultimate bearing capacity, which indicates that no slippage in the pile-soil interface occurs and the results of this analysis are valid. A comparison of the differential settlements and differential stresses on top of the pile group between initial design and scheme 1 is presented in Table 9. After the optimized design, the differential settlement decreased from $0.014 \mathrm{~m}$ to $0.005 \mathrm{~m}$, a $64 \%$ reduction, and the optimization objective was satisfied. Simultaneously, the differential stress on top of the pile group was reduced by $67 \%$. The average stress decreased from $6 \mathrm{MPa}$ to $5.8 \mathrm{MPa}$, a decrease of $3 \%$, with a $2 \%$ reduction in the average settlement; the result indicates that the vertical bearing capacity of the PRF did not decrease after optimization.

The results for the piles along sections A-A and B-B are selected for detailed comparison. Figure 10 presents the settlements and stresses on top of these piles; a detailed comparison of the corresponding data is shown in Table 10. The differential settlement is reduced by up to $82 \%$ along section A-A and by $79 \%$ along section B-B after optimized 
TABLE 7: Details of the calculation progress.

\begin{tabular}{lccccc}
\hline Site & $\begin{array}{c}\sigma_{i} \\
(\mathrm{MPa})\end{array}$ & $\begin{array}{c}\sigma_{\mathrm{j}} \\
(\mathrm{MPa})\end{array}$ & $\begin{array}{c}\sigma_{i}^{\prime} \\
(\mathrm{MPa})\end{array}$ & $d_{\mathrm{i}}(\mathrm{m})$ & $d_{i}^{\prime}(\mathrm{m})$ \\
\hline$\sigma_{i}=\sigma_{i, \max }$ & 7.1 & $6-0.25 \times(6-4.7)$ & 6.4 & 1.5 & 1.7 \\
$\sigma_{i}=\sigma_{i, \min }$ & 4.7 & $6+0.25 \times(7.1-6)$ & 7.4 & 1.5 & 1.3 \\
\hline
\end{tabular}

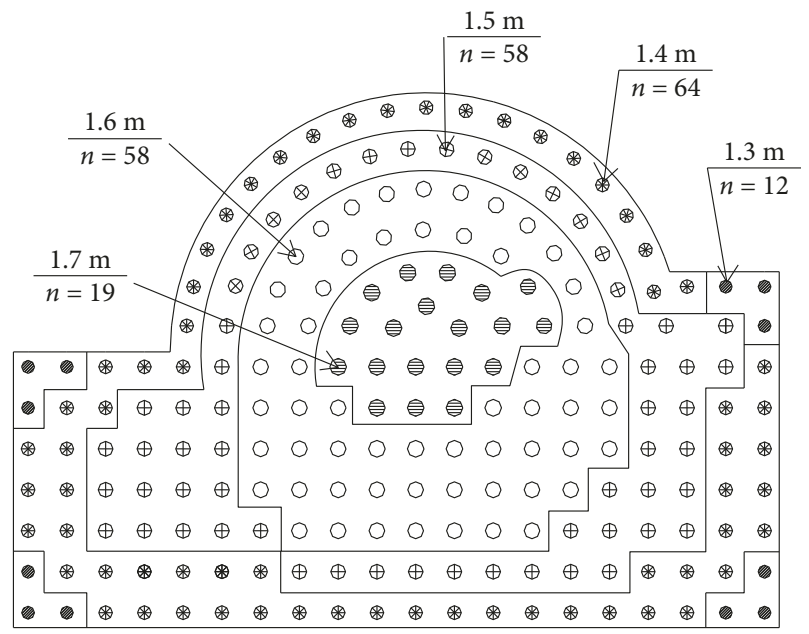

Figure 8: Final optimized configuration with different pile diameters (scheme 1).

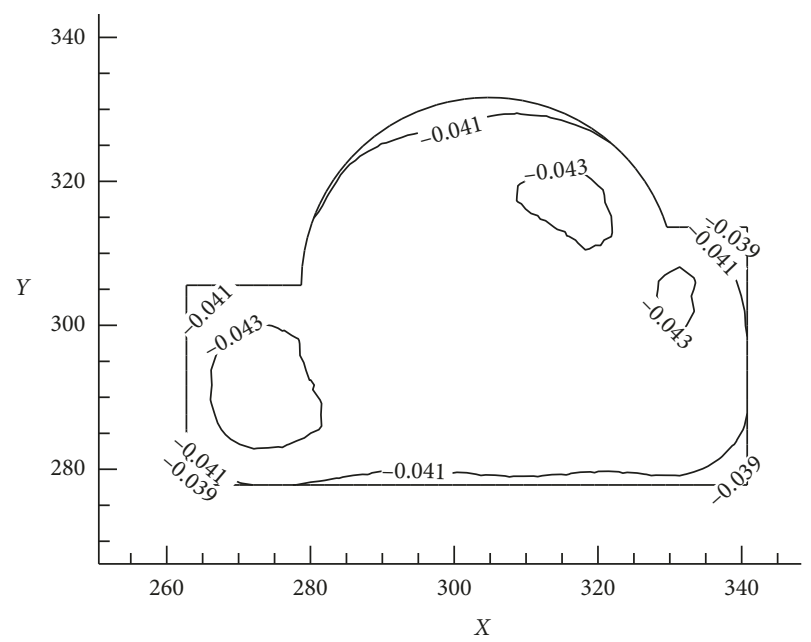

FIGURE 9: Settlement contour plots of rafts with different pile diameters (scheme 1) (m).

design; the differential stress is reduced by $56 \%$ along section $\mathrm{A}-\mathrm{A}$ and by $71 \%$ along section B-B. Therefore, a more uniform stress distribution on top of the piles is also obtained. The reason of this phenomenon is that piles with bigger diameters has more pile-soil contact areas and then will have higher bearing capacity. Under the same load, the greater the pile-soil contact area, the less settlement must be sacrificed and vice versa.

The reduction in differential settlement on top of the piles will affect the bending moment of the raft inevitably. Solid element cannot extract the bending moment directly, which is described by the integral bending moment of the raft in this paper; the method [34] for calculating the integral bending moment of the raft is described below. The basic formula for the relative bending $\theta_{\mathrm{r}}$ is

$$
\theta_{\mathrm{r}}=\frac{\Delta \omega_{\mathrm{r}}}{L_{\mathrm{R}}}
$$

where $\Delta \omega_{\mathrm{r}}$ is the differential settlement between the maximum and minimum settlements along a line on the raft and $L_{\mathrm{R}}$ is the length of the raft according to the location of the integral bending moment; different locations on the raft correspond to different values of $L_{\mathrm{R}}$ (see Figure 11).

According to the theory of elasticity, integral bending moments can be calculated by the raft thickness $t$ and the relative bending $\theta_{\mathrm{r}}$ as follows [34]:

$$
M_{L}=8 \theta_{\mathrm{r}} D_{\mathrm{r}}\left[\frac{1}{L}+\frac{\nu_{\mathrm{r}}}{B}\right]
$$

where $v_{\mathrm{r}}$ is Poisson's ratio of the raft, $L$ and $B$ are the length and width of the raft, respectively, and $D_{\mathrm{r}}$ is the bending stiffness and can be calculated as [34]

$$
D_{\mathrm{r}}=\frac{E_{\mathrm{r}} t^{3}}{12}\left(1-v_{\mathrm{r}}^{2}\right)
$$

where $E_{\mathrm{r}}$ is the elastic modulus of the raft.

The raft in this model has a thickness of $1.8 \mathrm{~m}$, an elastic modulus of $E_{\mathrm{r}}=2.0 \times 10^{10} \mathrm{~Pa}$, and Poisson's ratio of $v_{\mathrm{r}}=0.17$. The values of $L$ and $B$ are equivalent to a length of $75 \mathrm{~m}$ and width of $45 \mathrm{~m}$, respectively. The results of the integral bending moment of the raft along the $X$ axis and $Y$ axis are shown in Figure 12, and Table 11 presents the details of this comparison. The results demonstrate that the integral bending moment of the raft decreases considerably after optimized design. The reason can be found in Figures 9 and $7(a)$ : the settlement of the raft is more uniform than in the initial design after optimization, which results in the reduction of the differential settlement of the raft, and thus the corresponding integral bending moment will be reduced according to equations (12) and (13). The maximum $M_{x}$ and $M_{y}$ decrease by $52 \%$ and $78 \%$. The integral bending moments decrease not only along both axes but also more uniformly than initial design, with the average integral bending moments decreasing by $68 \%$ for the $X$ axis and $75 \%$ for the $Y$ axis. Therefore, the additional stress of the upper structure caused by the bending moment from the raft is reduced considerably, and the safety performance of the upper structure is improved.

6.2. Optimized Design under Various Pile Spacing. For the convenience of construction, a PRF that adopts one kinds of pile diameter is suitable, and the differential settlement of the raft can also be minimized by adjusting the spacing of the piles.

6.2.1. Procedure of the Optimized Design. The optimized design with different pile spacing is performed according to equation (8). In Figure 8, 19 piles with $d=1.7 \mathrm{~m}$ can be replaced by 24 piles $(24=19 \times(0.85 \times 0.85) /(0.75 \times 0.75))$ 
TABLE 8: Maximum load on top of piles with different diameters (results of scheme 1) and the corresponding ultimate bearing capacity.

\begin{tabular}{|c|c|c|c|c|c|}
\hline Pile diameter & $\begin{array}{c}d=1.3 \mathrm{~m} \\
(L=37 \mathrm{~m})\end{array}$ & $\begin{aligned} d & =1.4 \mathrm{~m} \\
(L & =37 \mathrm{~m})\end{aligned}$ & $\begin{array}{c}d=1.5 \mathrm{~m} \\
(L=37 \mathrm{~m})\end{array}$ & $\begin{array}{c}d=1.6 \mathrm{~m} \\
(L=37 \mathrm{~m})\end{array}$ & $\begin{array}{c}d=1.7 \mathrm{~m} \\
(L=37 \mathrm{~m})\end{array}$ \\
\hline Maximum pile top load (MN) & 8.2 & 9.5 & 11 & 12 & 13 \\
\hline Ultimate bearing capacity ${ }^{\mathrm{a}}(\mathrm{MN})$ & 15.2 & 16.2 & 17.2 & 18.2 & 19.2 \\
\hline
\end{tabular}

${ }^{a}$ The empirical value calculated by equation (10).

TABLE 9: Comparison of settlements and stresses on top of piles between different schemes.

\begin{tabular}{lcccc}
\hline Model & Diff. settlement $(\mathrm{m})$ & Diff. stress $(\mathrm{MPa})$ & Average settlement $(\mathrm{m})$ & Average stress $(\mathrm{MPa})$ \\
\hline Initial design & 0.014 & 2.4 & 0.043 & -6 \\
Different diameters $(F)$ & $0.005(64 \%)$ & $0.8(67 \%)$ & $0.042(2 \%)$ & $-5.8(3 \%)$ \\
Different spacing $(F)$ & $0.005(64 \%)$ & $0.9(63 \%)$ & $0.042(2 \%)$ & $-5.7(4 \%)$ \\
\hline
\end{tabular}

Note. "Diff." is short for differential.

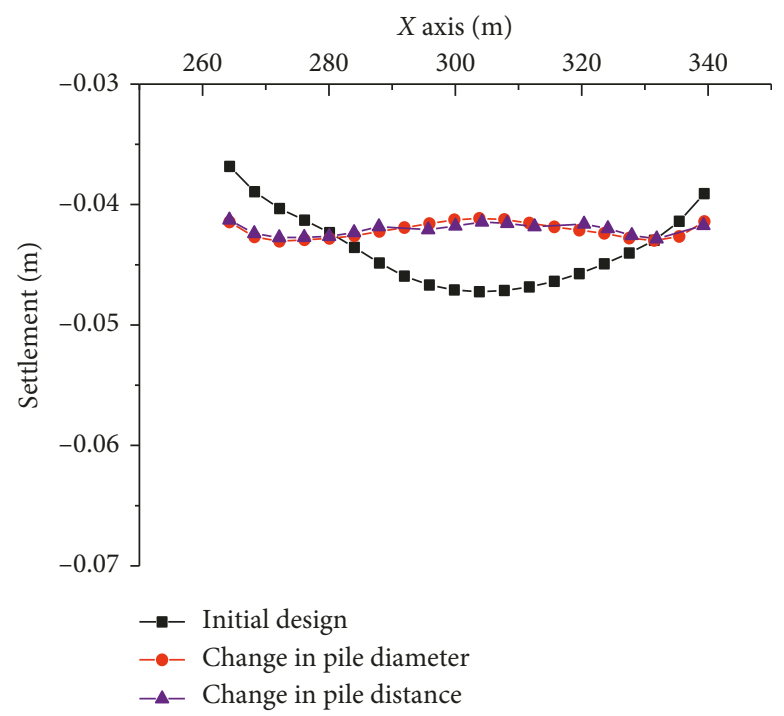

(a)

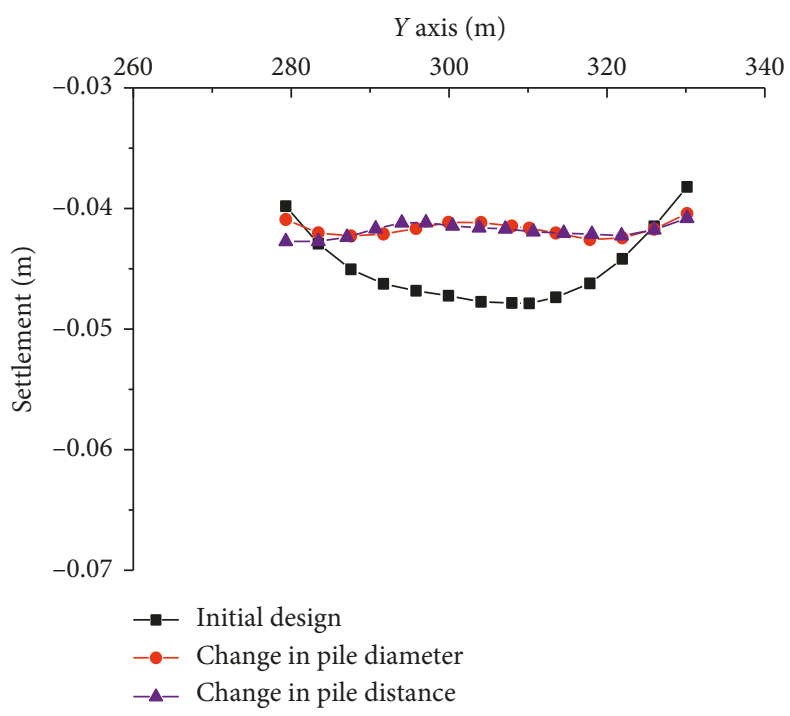

(c)

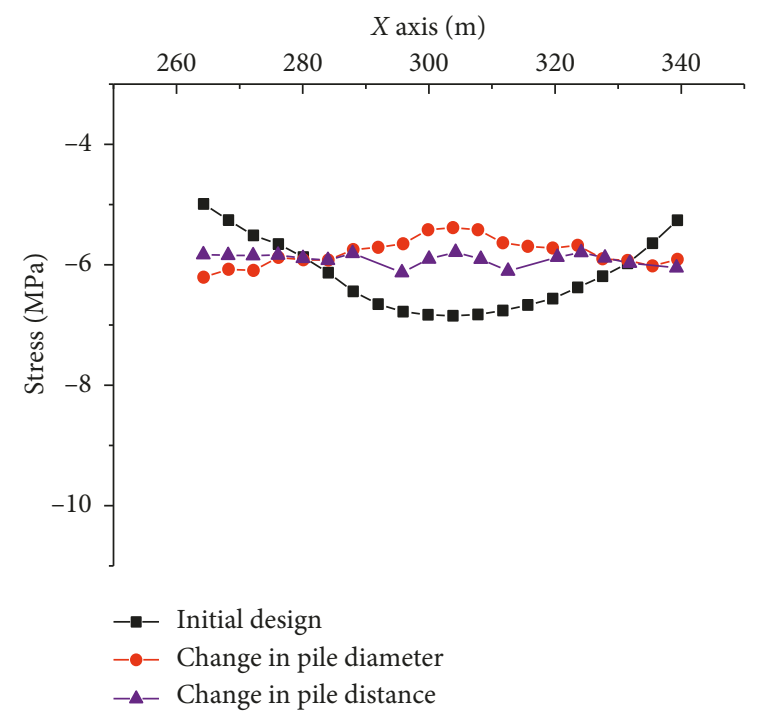

(b)

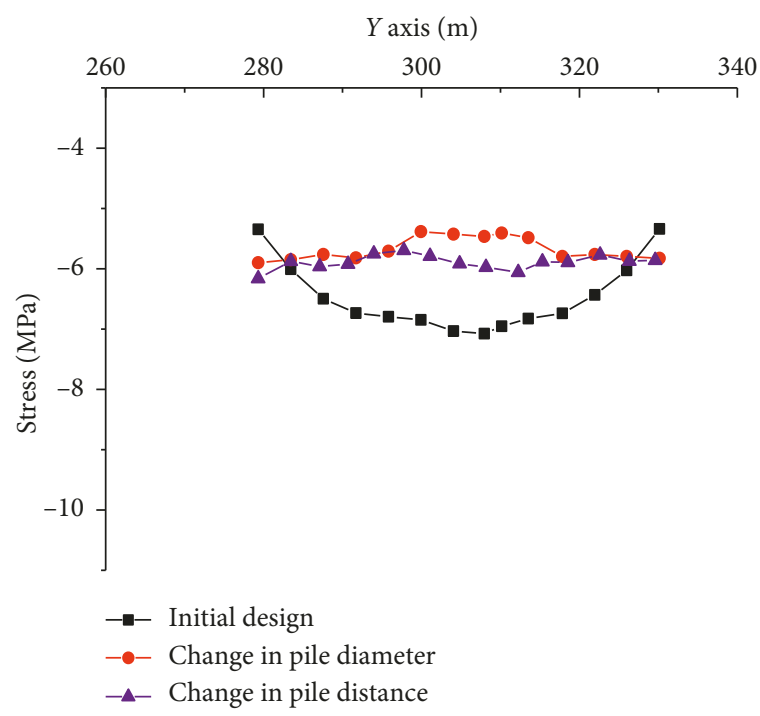

(d)

FIGURE 10: Comparison of the results of the initial design and optimized design: settlement distributions on top of the piles along (a) section A-A and (c) section B-B; stress distributions on top of the piles along (b) section A-A and (d) section B-B. 
TABLe 10: Details of the comparison between the initial design and optimal design.

\begin{tabular}{|c|c|c|c|c|}
\hline \multirow{2}{*}{ Model } & \multicolumn{2}{|c|}{ Differential settlement (m) } & \multicolumn{2}{|c|}{ Differential stress $(\mathrm{MPa})$} \\
\hline & Section A-A & Section B-B & Section A-A & Section B-B \\
\hline Initial design & 0.0104 & 0.0097 & 1.86 & 1.74 \\
\hline Different diameters $(F)$ & $0.0019(82 \%)$ & $0.002(79 \%)$ & $0.82(56 \%)$ & $0.51(71 \%)$ \\
\hline Different spacing $(F)$ & $0.0016(85 \%)$ & $0.0016(84 \%)$ & $0.44(76 \%)$ & $0.47(73 \%)$ \\
\hline
\end{tabular}

Note. The differential values are the difference between the maximum and minimum values of the piles along section A-A or B-B.

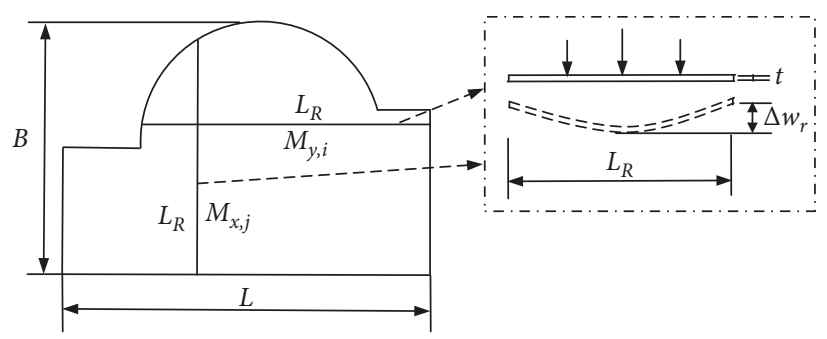

FIGURE 11: Sketch of integral bending moment calculation.

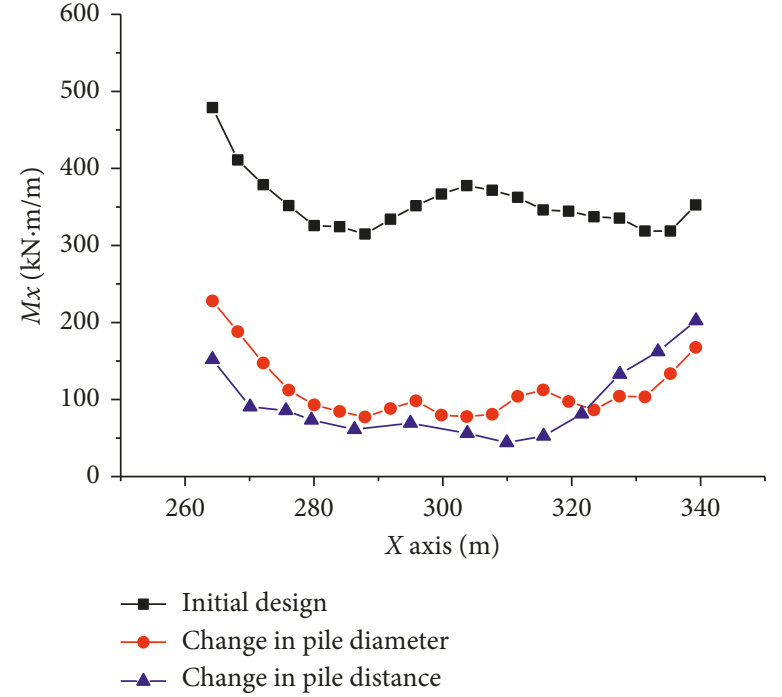

(a)

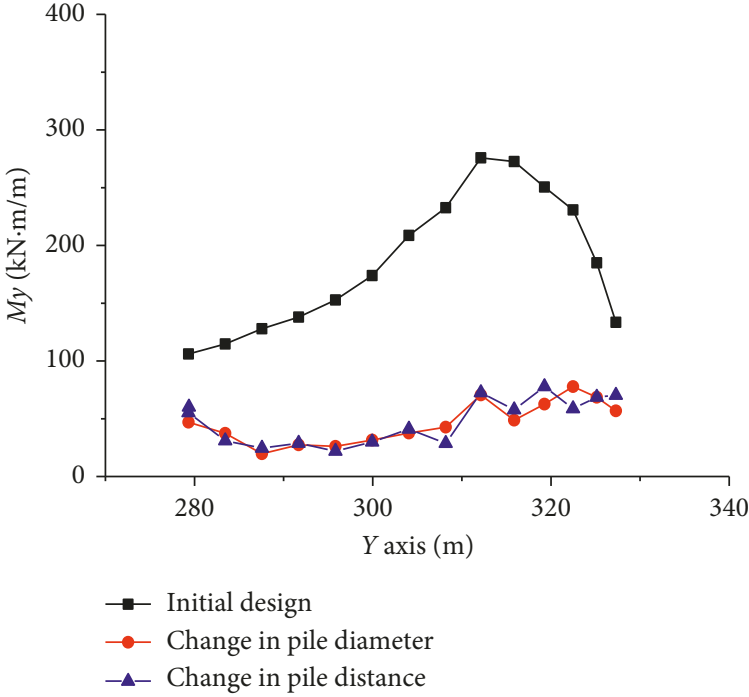

(b)

FIGURE 12: Integral bending moments of the raft along the (a) $X$ axis and (b) $Y$ axis.

TABLE 11: Comparison of integral bending moments.

\begin{tabular}{lcccc}
\hline Model & Average $M_{x}(\mathrm{kN} \cdot \mathrm{m} / \mathrm{m})$ & Max $M_{x}(\mathrm{kN} \cdot \mathrm{m} / \mathrm{m})$ & Average $M_{y}(\mathrm{kN} \cdot \mathrm{m} / \mathrm{m})$ & $\mathrm{Max} M_{y}(\mathrm{kN} \cdot \mathrm{m} / \mathrm{m})$ \\
\hline Initial design & 355 & 478 & 186 & 276 \\
Different diameters $(F)$ & $113(68 \%)$ & $228(52 \%)$ & $47(75 \%)$ & $78(72 \%)$ \\
Different spacing $(F)$ & $97(73 \%)$ & $202(58 \%)$ & $48(74 \%)$ & $78(72 \%)$ \\
\hline
\end{tabular}

with $d=1.5 \mathrm{~m}$, and the 24 new piles are evenly arranged. Similarly, 58 piles with $d=1.6 \mathrm{~m}$ are replaced by 66 piles with $d=1.5 \mathrm{~m}, 64$ piles with $d=1.3 \mathrm{~m}$ are replaced by 56 piles with $d=1.5 \mathrm{~m}$, and 12 piles with $d=1.4 \mathrm{~m}$ are replaced by 9 piles with $d=1.5 \mathrm{~m}$. The total number of piles with $d=1.5 \mathrm{~m}$ is 213. For only pile spacing can be changed, two piles were removed to ensure a total pile number of 211 . As a result, the number of piles and the pile diameter are same as in the initial design. In other words, the total material of the piles remains unchanged before and after optimized design.

After repeating step 8 twice, the optimization objective in step 7 is satisfied. Figure 13 shows the final pile arrangement with different pile spacing after optimization, i.e., scheme 2. 


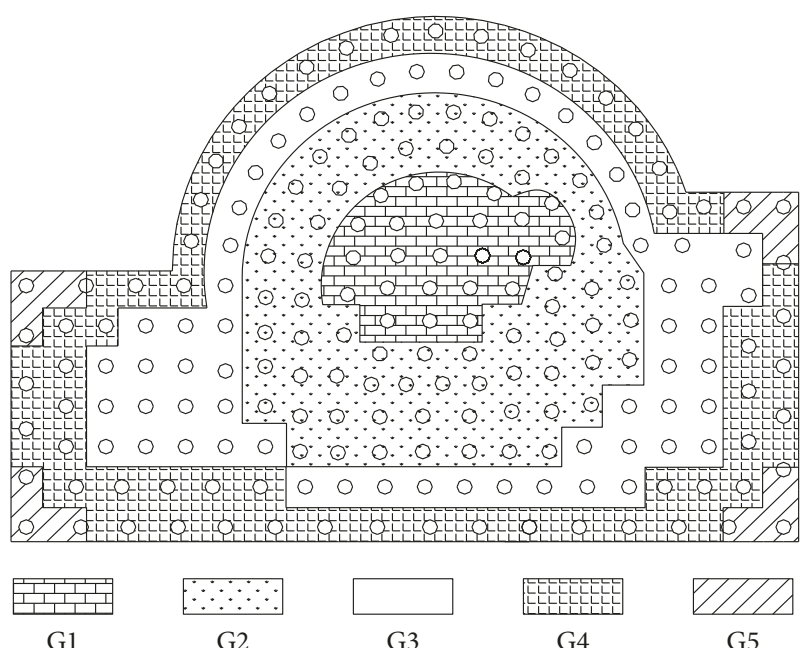

Figure 13: Final optimized configuration with different pile spacing (scheme 2).

6.2.2. FEM Calculated Results after Spacing Optimization. Figure 14 presents the settlement contours of the raft in scheme 2; the settlement contours of the raft are more uniform than initial design. The maximum pile top stress in scheme 2 is $6.4 \mathrm{MPa}(11.3 \mathrm{MN})$, which did not exceed its ultimate bearing capacity (17.2 MN) (Table 5). Table 9 presents a comparison of the differential settlement and differential stress on top of piles between the initial design and scheme 2 . In scheme 2, the differential settlement decreases by $64 \%$ and the optimization objective is achieved. The average stress decreased from $6 \mathrm{MPa}$ to $5.7 \mathrm{MPa}$, a decrease of $4 \%$, but the differential stress decreased by $63 \%$. Simultaneously, the average settlement of the raft decreased by only $2 \%$, and the vertical bearing capacity of the pile group increased slightly.

Because the positions of the piles in scheme 2 are different from those in scheme 1 and the initial design, the settlement and stress distribution on top of the piles near sections A-A and $\mathrm{B}-\mathrm{B}$ are selected to give a detailed comparison (Figure 10 and Table 10). Reducing the pile spacing is equivalent to increasing the number of piles in a certain area, and concentrated piles can increase the bearing capacity of this area; increasing the spacing of the piles near the boundary of the raft can decrease the bearing capacity in that area. Therefore, scheme 2 with different pile spacing can reduce the differential settlement by $85 \%$ along section A-A and by $84 \%$ along section B-B. The stress distribution on top of the piles are plotted in Figures $10(\mathrm{~b})$ and $10(\mathrm{~d})$. Note that the differential stress is reduced by $76 \%$ along section $\mathrm{A}-\mathrm{A}$ and by $73 \%$ along section $\mathrm{B}-\mathrm{B}$, which indicates that the stress distribution is more uniform than in the initial design. The results show that the optimized design with different pile spacing can redistribute the stresses on top of the piles into a more uniform state.

Comparisons of the integral bending moments along different directions of the rafts for different schemes are presented in Figure 12 and Table 11. The reason is similar to scheme 1; the settlement of the raft from scheme 2 in Figure 14 is more uniform than the initial design in

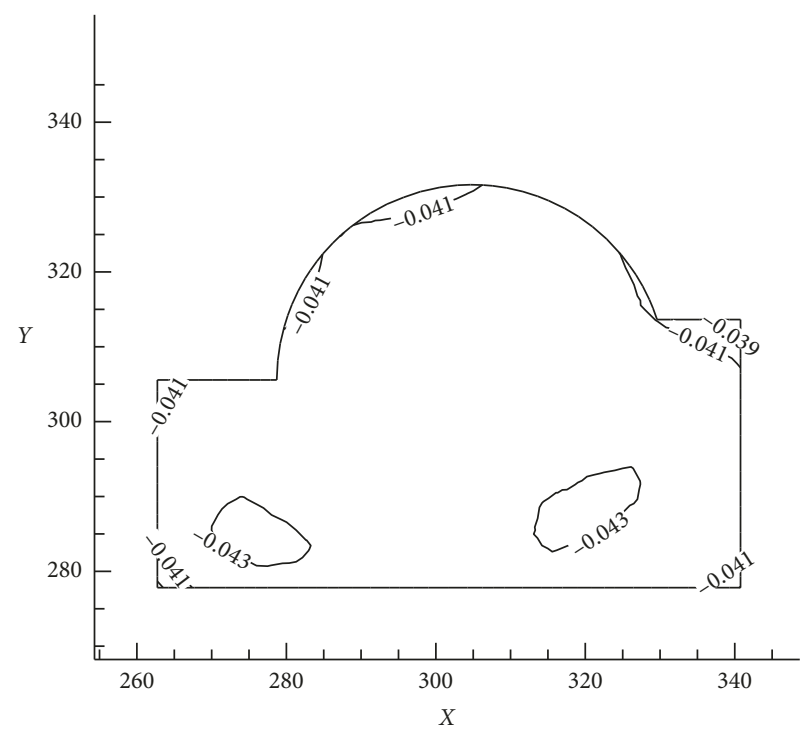

FIGURE 14: Settlement contour plots of rafts with different pile diameters (scheme 2) (m).

Figure 7(a); the differential settlement of the raft is also reduced, which then results in the decrease of the integral bending moment of the raft along both directions of scheme 2. The integral bending moments of the raft from scheme 2 decrease considerably in two directions, with the maximum $M_{x}$ and $M_{y}$ being reduced to $58 \%$ and $72 \%$. The average integral bending moment is reduced $73 \%$ for the $X$ axis and $74 \%$ for the $Y$ axis.

6.3. Comparison of Optimization Effects between Two Optimization Schemes. Table 9 shows the differential settlements of the pile group from two optimization schemes are the same; with optimization ratio $F$ equal to $64 \%$, the $F$ of the differential stress of the pile group is close, with $67 \%$ from scheme 1 and $63 \%$ from scheme 2 . The similar conclusion can be found in Figure 10 and Table 10, which plotted the differential settlement and differential stress in two directions. For the integral bending moment of the raft as is shown in Table 11, the result in scheme 2 is slightly better than in scheme 1 . The comparison of the optimization effects between two optimization schemes indicates that both optimization schemes can achieve the optimization objective, and the optimization effects are similar. Considering from the construction point of view, the optimization design via different pile diameters will indeed bring some difficulties during construction, such as need for more kinds of equipment for different pile diameters. Therefore, optimization via different pile spacing is a better choice in order to facilitate construction.

\section{Conclusions}

The purpose of this work is to determine an optimized configuration of a large PRF via the BSDPT optimization method given in this paper. This method adjusts the pile diameter and pile spacing according to the pile top stress to minimize differential settlement of the raft. In the process of 
implementation, piles are divided into several subgroups firstly according to the pile top stresses after the initial design. Then, the pile diameter is adjusted. Finally, the pile spacing of the pile foundation is adjusted based on optimized design with different pile diameters. The FE simulations of the loading process during superstructure construction are performed for the PRF with an initial layout, adjusted pile diameter layout, and adjusted pile spacing layout. A detailed comparison between the results of the optimized design and the initial design is provided. The following conclusions are drawn:

(1) Both optimized schemes reduced the differential settlement from $0.014 \mathrm{~m}$ to $0.005 \mathrm{~m}$, with a decrease of $64 \%$. The maximum integral bending moments were reduced from $478 \mathrm{kN} \mathrm{m} / \mathrm{m}$ to $228 \mathrm{kN} \mathrm{m} / \mathrm{m}$ for scheme 1 with a decreasing of $52 \%$ to $202 \mathrm{kN} \mathrm{m} / \mathrm{m}$ for scheme 2 with a decreasing of $58 \%$. Therefore, the additional stress of the upper structure caused by the deformation of the raft is reduced considerably, and the safety performance of the superstructure is improved.

(2) Two optimized design schemes indicate that for a given consumption of total pile material, the piled raft foundation behavior can be enhanced via different pile diameters or different pile spacing. These benefits can be used for economic savings and environmental impact reduction, as this strategy leads to a higher performance of the piled raft foundation for the same cost. In other words, for the same design standard, the optimized design uses less material.

(3) Both optimization schemes can achieve the optimization objective, and the optimization effects are close. However, scheme 2 with different pile spacing is more convenient during the construction. Together, compared with other optimization methods, the optimization method proposed in this paper is easier to use for the cases of complex loads or piles in irregular arrangements or large numbers.

The work in this article improves the overall performance of the foundation without increasing the project cost. Variable rigidity design has become an effective approach to the optimization of foundations; during such design, the distribution of the stiffness of the foundation is varied to accommodate the uneven load from the superstructure, and the pile-soil interaction and other complex factors are considered. However, after the optimization of the foundation, whether there is any effect on the response of the superstructure under a seismic load requires further research.

\section{Data Availability}

The data used to support the findings of this study are available from the corresponding author upon request.

\section{Conflicts of Interest}

The authors declare that there are no conflicts of interest regarding the theoretical and numerical observations introduced in this paper.

\section{Acknowledgments}

This work was supported by the National Key Research and Development Project (grant no. 2016YFB0201001).

\section{References}

[1] D. D. C. Nguyen, D.-S. Kim, and S.-B. Jo, "Parametric study for optimal design of large piled raft foundations on sand," Computers and Geotechnics, vol. 55, pp. 14-26, 2014.

[2] Y. K. Chow and V. Thevendran, "Optimisation of pile groups," Computers and Geotechnics, vol. 4, no. 1, pp. 43-58, 1987.

[3] P. Clancy and M. F. Randolph, "An approximate analysis procedure for piled raft foundations," International Journal for Numerical and Analytical Methods in Geomechanics, vol. 17, no. 12, pp. 849-869, 1993.

[4] J. Liu, "The modified model of pile-soil deformation calculation and variable rigidity design method for balance settlement," Chinese Journal of Geotechnical Engineering, vol. 22, no. 2, pp. 151-157, 2000, in Chinese.

[5] F.-Y. Liang, L.-Z. Chen, and X.-G. Shi, "Numerical analysis of composite piled raft with cushion subjected to vertical load," Computers and Geotechnics, vol. 30, no. 6, pp. 443-453, 2003.

[6] F. Liang, L. Chen, and J. Han, "Integral equation method for analysis of piled rafts with dissimilar piles under vertical loading," Computers and Geotechnics, vol. 36, no. 3, pp. 419-426, 2009.

[7] F. Liang and Z. Song, "BEM analysis of the interaction factor for vertically loaded dissimilar piles in saturated poroelastic soil," Computers and Geotechnics, vol. 62, pp. 223-231, 2014.

[8] X. Han, Y. Li, J. Ji, J. Ying, W. Li, and B. Dai, "Numerical simulation on the seismic absorption effect of the cushion in rigid-pile composite foundation," Earthquake Engineering and Engineering Vibration, vol. 15, no. 2, pp. 369-378, 2016.

[9] S. Shrestha, N. Ravichandran, and P. Rahbari, "Geotechnical design and design optimization of a pile-raft foundation for tall onshore wind turbines in multilayered clay," International Journal of Geomechanics, vol. 18, no. 2, article 04017143, 2017.

[10] M. H. Baziar, F. Rafiee, and C. J. Lee, "Effect of superstructure on the dynamic response of nonconnected piled raft foundation using centrifuge modelling," International Journal of Geomechanics, vol. 18, no. 10, pp. 369-378, 2018.

[11] C. Padfield and M. Sharrock, Settlement of Structures on Clay Soils, Construction Industry Research \& Information Institute, London, UK, 1983.

[12] K. Z. Truman and A. S. Hoback, "Optimization of steel piles under rigid slab foundations using optimality criteria," Structural Optimization, vol. 5, no. 1-2, pp. 30-36, 1992.

[13] M. Randolph, "Design methods for pile groups and piled rafts," in Proceedings of the XIII ICSMFE, New Delhi, India, May 1992.

[14] D. D. C. Nguyen, D. S. Kim, and S. B. Jo, "Settlement of piled rafts with different pile arrangement schemes via centrifuge tests," Journal of Geotechnical and Geoenvironmental Engineering, vol. 139, no. 10, pp. 1690-1698, 2013.

[15] H. Kim, H. Yoo, and I. Kang, "Genetic algorithm- based optimum design of piled raft foundations with model tests," Geotechnical Engineering, vol. 33, no. 1, pp. 1-11, 2002.

[16] S. Valliappan, V. Tandjiria, and N. Khalili, "Design of raft-pile foundation using combined optimization and finite element approach," International Journal for Numerical and Analytical Methods in Geomechanics, vol. 23, no. 10, pp. 1043-1065, 1999. 
[17] X. D. Cao, I. H. Wong, and M.-F. Chang, "Behavior of model rafts resting on pile-reinforced sand," Journal of Geotechnical and Geoenvironmental engineering, vol. 130, no. 2, pp. 129138, 2004.

[18] V. Fioravante and D. Giretti, "Contact versus noncontact piled raft foundations," Canadian Geotechnical Journal, vol. 47, no. 11, pp. 1271-1287, 2010.

[19] A. Eslami and S. S. Malekshah, "Analysis of non-connected piled raft foundations (NCPRF) with cushion by finite element method," Computational Methods in Civil Engineering, vol. 2, no. 2, 2011.

[20] A. Sinha and A. Hanna, "3D numerical model for piled raft foundation," International Journal of Geomechanics, vol. 17, no. 2, article 04016055, 2016.

[21] F. Basile, "Non-linear analysis of vertically loaded piled rafts," Computers and Geotechnics, vol. 63, pp. 73-82, 2015.

[22] C. M. Chan, L. M. Zhang, and J. T. Ng, "Optimization of pile groups using hybrid genetic algorithms," Journal of Geotechnical and Geoenvironmental Engineering, vol. 135, no. 4, pp. 497-505, 2009.

[23] K. N. Kim, S.-H. Lee, K.-S. Kim, C.-K. Chung, M. M. Kim, and H. S. Lee, "Optimal pile arrangement for minimizing differential settlements in piled raft foundations," Computers and Geotechnics, vol. 28, no. 4, pp. 235-253, 2001.

[24] F. Tradigo, F. Pisanò, C. di Prisco, and A. Mussi, "Non-linear soil-structure interaction in disconnected piled raft foundations," Computers and Geotechnics, vol. 63, pp. 121-134, 2015.

[25] N. Ravichandran, S. Shrestha, and K. Piratla, "Robust design and optimization procedure for piled-raft foundation to support tall wind turbine in clay and sand," Soils and Foundations, vol. 58, no. 3, pp. 744-755, 2018.

[26] T. Jiang, Three Dimensional Non-Linear Finite Element Analysis of the Pile-Group Effect for Large-Diameter and Super-Long Pile-Group Foundation, Hohai University, Nanjing, China, 2007, in Chinese.

[27] K. J. Bentley and M. H. E. Naggar, "Numerical analysis of kinematic response of single piles," Canadian Geotechnical Journal, vol. 37, no. 6, pp. 1368-1382, 2000.

[28] S. P. Chen, W. J. Yao, and S. Q. Zhu, "Nonlinear finite element analysis of super-long pile and soil interaction in soft soil," Advanced Materials Research, vol. 201-203, pp. 1601-1605, 2011.

[29] J. M. Duncan and C. Y. Chang, "Nonlinear analysis of stress and strain in soils," Journal of the Soil Mechanics and Foundations Division, vol. 96, no. 5, pp. 1629-1653, 1970.

[30] JGJ94-2008, Technical Code for Building Pile Foundations, Ministry of Housing and Urban-Rural Development of the People's Republic of China, Beijing, China, 2008.

[31] H. G. Poulos, "Piled raft foundations: design and applications," Géotechnique, vol. 51, no. 2, pp. 95-113, 2001.

[32] L. D. Sanctis, A. Mandolini, G. Russo, and C. Viggiani, "Some remarks on the optimum design of piled rafts," in Proceedings of the International Deep Foundations Congress, pp. 405-425, Orlando, FL, USA, February 2002.

[33] Y. Tang and X. Zhao, "121-story Shanghai Center Tower foundation re-analysis using a compensated pile foundation theory," The Structural Design of Tall and Special Buildings, vol. 23, no. 11, pp. 854-879, 2014.

[34] J. G. Dong and X. H. Zhao, Theory and Practice of Foundation Interaction of High-Rise Buildings, Tongji University Press, Beijing, China, 1997. 


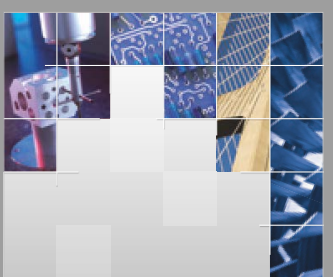

\section{Enfincering}
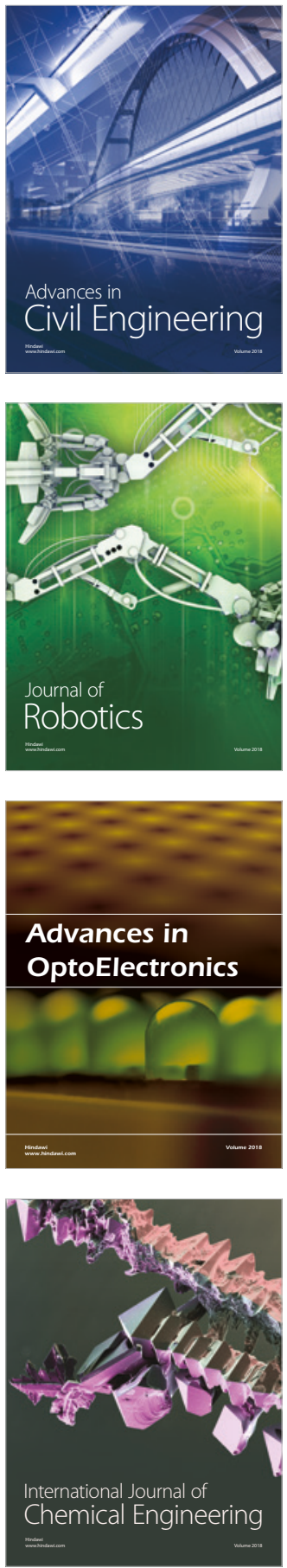

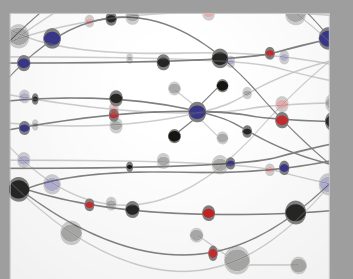

\section{Rotating \\ Machinery}

The Scientific World Journal

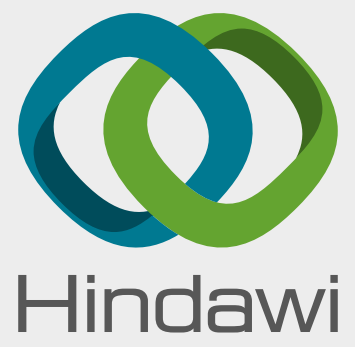

Submit your manuscripts at

www.hindawi.com
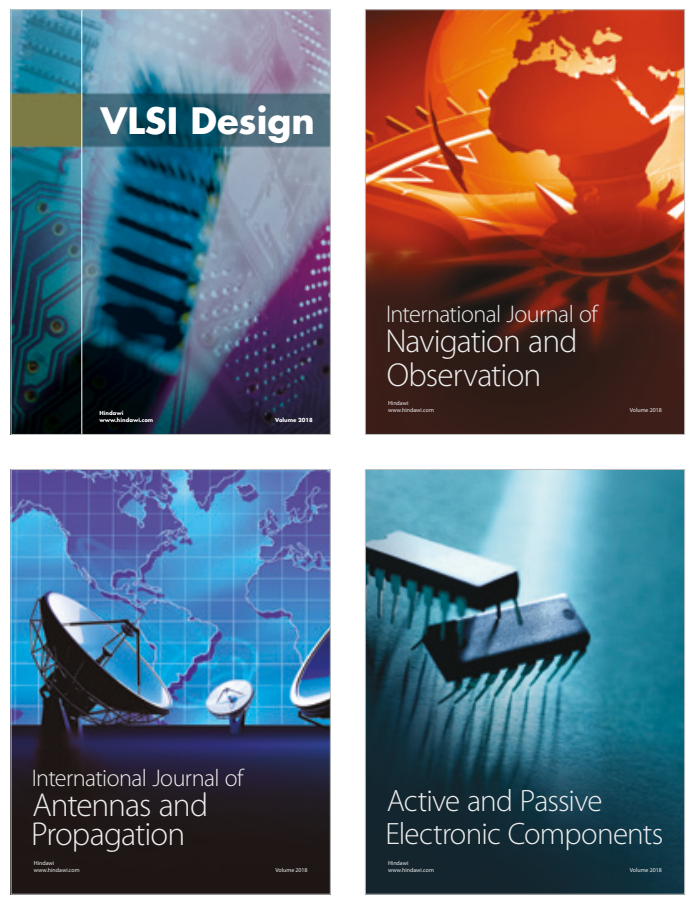
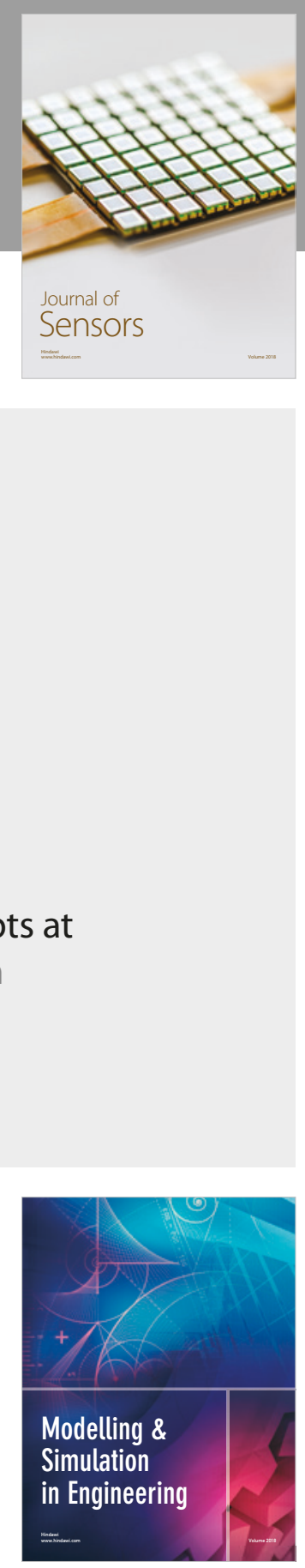

\section{Advances \\ Multimedia}
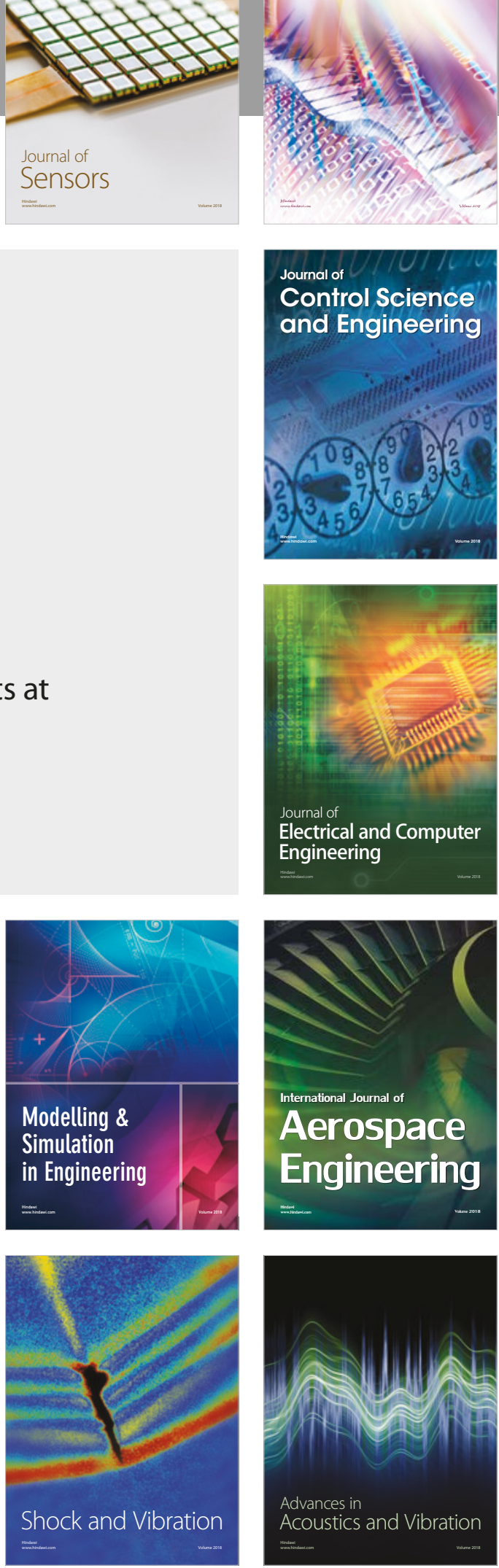